\title{
ERRATUM
}

\section{Extent of resection, molecular signature, and survival in 1p19q-codeleted gliomas}

TO THE READERSHIP: An error appeared in the article by Garton et al. (Garton ALA, Kinslow CJ, Rae AI, et al. Extent of resection, molecular signature, and survival in 1p19q-codeleted gliomas. J Neurosurg. Published online May 8, 2020. doi:10.3171/2020.2.JNS192767).

In the Results section of the Abstract, the last sentence was incorrect. The correct sentence appears below.

STR and GTR were independent predictors of improved survival in historically classified oligodendrogliomas (HR 0.83, p = 0.18; HR 0.69, p = 0.01 , respectively) and in $1 \mathrm{p} / 19 \mathrm{q}$-codeleted tumors (HR 0.49, p $<0.01$; HR 0.43, p $<0.01$, respectively).

The article has been corrected online as of June 5, 2020.

Andrew L. A. Garton, MD NewYork-Presbyterian Hospital/Weill Cornell Medical Center, New York, NY

Connor J. Kinslow, MD

Tony J. C. Wang, MD

Vagelos College of Physicians and Surgeons, NewYork-Presbyterian Hospital/Columbia University Irving Medical Center, New York, NY

CORRESPONDING ARTICLE See pp 1357-1367.

INCLUDE WHEN CITING

Published online June 5, 2020; DOI: 10.3171/2020.5.JNS192767a.

CAANS 2021, except where prohibited by US copyright law 